dispensing, as less than the optimal way of delivering a pharmacy service because communication may be compromised. The Board recognises, however, that there are circumstances where these forms of communication are necessary in, or appropriate to, the patient's circumstances (e.g. in remote areas).

A pharmacist supplying medicines indirectly to a patient must comply with all relevant State or Territory, and Commonwealth legislation, the Pharmacy Board of Australia's Guidelines for Dispensing of Medicines, and established practice and quality assurance standards.?

The Australian Therapeutic Goods Administration (TGA) also publishes a warning regarding the potential dangers of online pharmacies (usually overseas) but does not conduct any regulatory review of internet sites. ${ }^{8}$ The TGA's position assists consumers in having greater confidence in Australian online pharmacy sites rather than those overseas.
Online ordering of medicines by consumers will remain a feature of the Australian pharmacy landscape, and high operational and professional requirements should ensure that medicines ordered from Australian registered online pharmacies meet Australian standards. Conversely, non-Australian sites offer little in the way of reassurance.

Australian health consumers should be vigilant of online pharmacies and standards and guidelines of the Pharmacy Board of Australia, the Pharmaceutical Society of Australia, and the accreditation requirements of the Quality Care Pharmacy Program need to be maintained. There should be appropriate governance of access to medicines, whether that be through a traditional walk-in pharmacy or via an online transaction. $<$

Bill Kelly is a practitioner member of the Pharmacy Board of Australia and is the executive director of the Australian Friendly Societies Pharmacies Association.

\title{
REFERENCES
}

1. Therapeutic Goods Administration. Personal importation scheme. Canberra: Department of Health; 2015.

www.tga.gov.au/personal-importation-scheme [cited 2015 Aug 12]

2. Internet pharmacies: Most rogue sites operate from abroad, and many sell counterfeit drugs. Washington (DC): US Government Accountability Office; 2014 WWw.gao.gov/products/GAO-14-386T [cited 2015 Aug 12]

3. Alwon BM, Solomon G, Hussain F, Wright DJ. A detailed analysis of online pharmacy characteristics to inform safe usage by patients. Int J Clin Pharm 2015;37:148-58.

4. Dudley J. The Internet Pharmacy. Presentation from the 46th AESGP Annual Meeting, Dubrovnik 2010. Slideshare.net; 2012. www.slideshare.net/JameswDudley/mail-order-and-internet-pharmacyaesgp-presentation-james-dudley [cited 2015 Aug 12]
5. Websites closed in battle against illegal trade in medicines [press release] London: Medicines and Healthcare Products Regulatory Agency; 2015. www.gov.uk/government/news/websites-closed-in-battle-against-illegaltrade-in-medicines [cited 2015 Aug 12]

6. The Pharmaceutical Society of Australia. Professional Practice Standards Version 4 - June 2010. Canberra: Pharmaceutical Society of Australia; 2010. www.psa.org.au/download/standards/professional-practice-standards-v4.pdf [cited 2015 Aug 12]

7. Pharmacy Board of Australia. Guidelines for dispensing of medicines. Melbourne: Pharmacy Board of Australia; 2010. www.pharmacyboard.gov.au/Codes-Guidelines.aspx [cited 2015 Aug 12]

8. Therapeutic Goods Administration. Buying medicines and medical devices over the internet. Canberra: Department of Health; 2015. www.tga.gov.au/community-qa/buying-medicines-and-medical-devicesover-internet [cited 2015 Aug 12]

\section{Online pharmacies: a consumer perspective}

While the power of the internet has proved a terrific boon for consumers seeking bargains and otherwise inaccessible products, pharmacy is one online sector where the benefits are mixed. The uninitiated consumer can encounter both health and financial hazards.

From a consumer's point of view, online pharmacies seem to offer much potential value, although not necessarily on price. For housebound patients, the option of ordering medication from home and having it delivered to the door is obvious. For those living in remote areas, and consumers who are short of time and for whom reaching the pharmacy is difficult, ordering online has obvious advantages. There are also those seeking personal products who prefer anonymity.
The rewards and risks of online pharmacy shopping present a significant issue for consumer health. Two national regulatory authorities have issued detailed warnings about online pharmacies, but stopping overseas online pharmacy scams is no simple task.

The Australian Competition and Consumer Commission states there are legitimate online pharmacies that list full contact details and require valid prescriptions. However, it warns there are scams and spam emails offering medicines at very cheap prices, or without the need for prescriptions, that can cause financial and health problems.

Questions surrounding international sites selling sildenafil and other products without prescription,

\section{Leanne Wells}

Chief executive officer Consumers Health Forum of Australia

Aust Presc 2015;38:187-8

First published online 26 August 2015 
contrary to Australian law, reflect the difficulty of ensuring the safety of overseas online pharmacies.

The Therapeutic Goods Administration also warns consumers to be cautious, and points to the risk of unexpected and potentially serious adverse reactions. Given the potential for health risks for the unwary, it is concerning that there are no regulatory reviews of pharmacy sites. There is therefore a need for ongoing education by authorities on the risks of online pharmacies.

Wherever possible it is preferable for consumers to obtain their prescription medicines at a traditional pharmacy, particularly when the prescription is for a new drug or for a serious condition. Even for over-thecounter products, it is wise to buy from a pharmacy to hear of any safety advice first-hand.

The reality is that, for an increasing number of people, given population ageing and the rise in chronic illness, online pharmacies will likely become an ever more favoured option. In Australia the online market is already dominated by well-known, presumably safe, Australian pharmacy chains.

The proliferation of online pharmacy prescription services, and now online medical consultation services, points to another dilemma that seems set to become more prevalent. That is, the growing number of remote health assessments made possible by internet and telehealth where the doctor, pharmacist or other practitioner is not seeing the patient in person. It seems that circumstances, including time and commercial pressures, are combining to make these virtual consultations ever more frequent.

The question for consumers and practitioners is how do we ensure that the overall result of the shift to virtual consultations and prescriptions will benefit our health? $<$

\section{Letters to the Editor}

\section{Concerns about quetiapine}

As a psychiatrist in private practice, I share some of the concerns about quetiapine raised by Jonathan Brett (Aust Prescr 2015;38:95-7). However, I think there is a significant role for off-label prescribing in certain patient groups. Patients with major depression, particularly those with agitation, high degrees of inner distress, or sleep difficulties often benefit substantially when quetiapine, usually 12.5-100 mg, is added to their antidepressant. The $25 \mathrm{mg}$ tablet is most appropriate for this use.

If it is claimed that 'quetiapine has proven safety and efficacy when used for its approved indications', which usually entail 400-800 mg doses, I do not think further studies are needed to conclude a $25 \mathrm{mg}$ dose will be safer than a 400-800 mg dose. As it is, undertreating a depressed patient's distress also carries significant risks. These risks are difficult to analyse as depressed patients who become suicidal usually get booted out of depression studies. As a result, there is a significant validity issue regarding the 'evidence' because patients who participate in depression studies differ from many of those who come through a psychiatrist's door. Indeed, those most at risk of suicide are the ones we tend to have the least evidence about to guide our management. The 'no evidence, so don't use it' mantra may well work against the welfare of many depressed patients.
Evidence is a tool, not a god, and the flaws in the evidence need to be fully understood before 'evidence' is used to formulate management guidelines.

Another area concerns personality disorders, which are difficult to treat. Psychological treatment should be the mainstay, but many patients are not very psychologically minded, and psychological treatment doesn't always work, even among those who want to change. Yet patients with personality disorders often have high levels of distress. The 'no evidence, so don't use it' mantra may again work against patient welfare, compared to the judicious use of low-dose quetiapine for such patients when they are in crisis.

Thus, quetiapine has its problems, but off-label use remains an important tool in certain clinical situations.

\section{Alan Garrity \\ Psychiatrist \\ Dee Why, NSW}

I would like to comment, as a GP, on Jonathan Brett's very timely article. I have a sizeable geriatric population in my practice, of which a fair number with evolving or full-blown dementia are in institutions. This is the area in which quetiapine use is relevant. Quetiapine 6.25-100 mg per day is very 